\title{
The Possible Effect of DHEA on Hepatic and Metabolic Dysfunction in a Rat Model of Male Hypogonadism
}

\author{
HATEM BIN MOHAMMED AL-NAABI, M.D. ${ }^{\mathbf{~}}$; HUSSEIN F. SAKR, M.D. ${ }^{\mathbf{1}}, \mathbf{2}$ and AHMED M. SHATA, M.D. ${ }^{\mathbf{4}},{ }^{\mathbf{2}}$ \\ The Department of Physiology, College of Medicine and Health Sciences, Sultan Qaboos University, Muscat, Oman ${ }^{\mathbf{I}}$, \\ The Departments of Medical Physiology , Clinical Pharmacology ${ }^{3}$, Faculty of Medicine, Mansoura University, Mansoura and \\ The Department of Pharmacy Practice, Faculty of Pharmacy, Delta University, Gamasa ${ }^{4}$, Egypt
}

\begin{abstract}
Background: Male hypogonadism is characterized by androgen deficiency in the body. Several studies have shown that testosterone deficiency is inducing a metabolic syndrome and insulin resistance. Although of the unwanted effects of exogenous testosterone replacement therapy, it is the main treatment of male hypogonadism. One of the safe treatment options is Dehydroepiandrosterone (DHEA) replacement therapy which is the precursor of testosterone. Up to date and to the best of our knowledge, no one investigates the effect of DHEA on glucose-6-phosphatase enzyme in a rat model of male hypogonadism and its impact on the metabolic dysfunction.

Aim of Study: The aim of the research is to investigate the possible protective effect of DHEA on hepatic and metabolic dysfunction in a rate model of male hypogonadism through examining its effect on glucose-6-phosphatase enzyme. Moreover, it studies the possible therapeutic effects of the male androgen (DHEA) on the hepatic steatosis and insulin resistance triggered by testosterone deficiency.

Material and Methods: Thirty-two Wistar Kyoto rats were divided into 4 groups as follows (I) Untreated controls, (II) Untreated orchidectomized, (III) Control, treated with DHEA and (IV) Orchidectomized, treated with DHEA. Treatment was carried three times per week for 12 weeks. Cobas c111, Roche diagnostic, USA machine was used to measure the level of the glucose, liver enzymes and lipid profile. EnzymeLinked Immunosorbent Assay (ELISA) was used to measure the plasma level of testosterone hormone, insulin and glucose6-phosphatase enzyme.
\end{abstract}

Results: As expected, the plasma testosterone decreased significantly in ORCH rats, with significant increase in glucose, lipid profile as well as significant decrease in insulin as compared to control rats. Moreover, our data revealed insignificant increases in plasma testosterone in $\mathrm{ORCH}+$ DHEA with significant increase in ORCH + DHEA compared to control + DHEA. DHEA did not significantly affect G-6-Pase enzyme. Also, $\mathrm{ORCH}$ shows significant increase in triglyceride and cholesterol as well as the ORCH + DHEA.

Correspondence to: Dr. Ahmed Shata, E-Mail: ahmedmhes@mans.edu.eg
Conclusion: Testosterone deficiency and DHEA replacement therapy have no effects on glucose 6-phosphatase enzyme. Male hypogonadism is a risk factor for metabolic syndrome and NAFLD that could not be treated effectively with DHEA.

Key Words: DHEA-Hepatic-Metabolic-Hypogonadism.

\section{Introduction}

A COMBINATION of physical inactivity and unhealthy diet intake are characteristic of our modern lifestyle. The positive energy balance is a major cause for obesity and eventually result in development of insulin resistance and the metabolic syndrome. As the key metabolic organ, the liver develops obesity-related complications [1,2] NAFLD has a wide spectrum of fatty liver changes ranging from hepatic steatosis to Non-Alcoholic Steatohepatitis (NASH), which can complicated by fibrosis, cirrhosis, liver failure, and even hepatocellular carcinoma $[3,4]$. NAFLD markedly increase among different population but its pathogenesis still poorly understood. NASH, is 6 times more prevalent in both obesity and the metabolic syndrome and also, in Insulin Resistance (IR) as evidenced by autopsy data $[\mathbf{5 , 6 ]}$.

Male hypogonadism associated with decreased serum testosterone level has a high frequency in men with diabetes mellitus and metabolic syndrome [7]. Furthermore, decreased serum androgens mainly testosterone is linked with insulin insenstivity, central obesity, increased LDL-cholesterol, hypertension, hypercoagulability, hypofibrinolysis, decreased cardiac performance and ischemic heart disease [8]. About 50\% of men with T2DM have testicular failure [7]. Previous studies showed there is a great association between male hypogonadism and metabolic syndrome [9-11] .

The connection between male hypogonadism and metabolic syndrome is uncertain with obesity- 
induced androgen deficiency. The relation between them appeared to bidirectional as discussed by Laaksonen et al., 2005 [12], metabolic syndrome and insulin resistance contribute in the pathogenesis of male hypogonadism. On the other hand, male hypogonadism is common in male patient with type $2 \mathrm{DM}$ and metabolic syndrome.

Testosterone is metabolized by the enzymatic reaction that catalyzed by aromatase in adipose tissue to $17 \mathrm{~b}$ oestradiol (E2). Decrease of testosterone levels enhance adipocyte quantity and fat accumulation, which gradually leads to more inhibitory effect on testosterone levels. Additionally, aromatization of testosterone either in peripheral adipose tissue or centrally to E2, play a major role in induction of negative feedback of testosterone on the hypothalamo-pituitary axis [13].

Thus, in overweight and obese men, increased and upregulated aromatase activity in fat cells is associated with decreased testosterone secretion secondary to pituitary dysfunction due to suppression of gonadotrophin-mediated testosterone secretion that further leading to progressive hypogonadism. Another explanation of hypogonadism in insulin resistance is the role of the adipocytokines as IL-6, TNF-alpha and leptin. Circulating adipocytokines inhibits the hypothalamic-pituitary testicular axis [14] . Furthermore, leptin inhibits the Leydig cells of the testis to reduce testosterone synthesis [15]. Furthermore there are contributory effects of increasing insulin resistance on decrease of Leydig cell testosterone secretion in men [16].

DHEA and DHEAS are pre-hormones. DHEAS is hydrophilic and constitutes a circulating stock. In peripheral tissues, only lipophilic DHEA can be converted to other androgens and estrogens [17] At a tissue level and according to its local needs, steroid production permits an auto-regulation of the local hormonal environment, with less systemic effects [18]. This phenomenon is called intracrinology. In the ladies before menopause, majority of estrogens and most androgens are derived from DHEA through intracrine mechanisms, however, at a tissue level, all androgens and estrogens are synthesized in post-menopausal period. On the contrary, testes secrete androgens throughout life and local hormone production is still present but is more difficult to be assessed [17,19].

The effects of DHEA are regulated by downstream metabolism of DHEA to sex steroids. Insulin resistance and abdominal obesity are common in polycystic ovary syndrome due to elevated circulating androgen levels. On the contrary, multiple researches have elucidated that DHEA effectively affect whole body composition and several metabolic parameters in murine studies that are attributable to its direct impact on adipocyte biology, beside other metabolic tissues such as muscle and liver. So, in our current study, we aim to investigate the possible protective effect of DHEA on hepatic and metabolic dysfunction in a rat model of male hypogonadism and study the possible therapeutic effects of the male androgen (DHEA) on the hepatic steatosis and insulin resistance.

\section{Material and Methods}

For this experimental animal study, the ethical approval was granted by the Ethical Committee of the College of Medicine and Health Sciences of Sultan Qaboos University (SQU) with the number SQU/AEC/2017/18/01 and according to the guide of laboratory animals prepared by Mansoura Medical Research Ethics Committee, Egypt.

\section{Animals:}

Thirty-two Wistar Kyoto rats were used in the present study and their ages were between (12-14 weeks) and weighed between 200-300gm. All rats were provided from the small animal house in SQU where they were kept under controlled conditions. The study was performed in Physiology Department 2017 at College of Medicine and Health sciences, Sultan Qaboos University.

\section{Experimental design:}

The rats were divided into 4 equal groups as follows:

- Group I/Control Group (CON): Included 8 normal male Wistar Kyoto rats, and served as a control.

- Group II/Orchiectomized Group (ORCH): Included 8 normal male Wistar Kyoto rats, undergone bilateral orchidectomy.

- Group III (CON + DHEA): Included 8 normal male Wistar Kyoto rats, treated orally with DHEA $(30 \mathrm{mg} / \mathrm{kg})$ three times weekly for 12 weeks.

- Group IV (OR CH + DHEA): Included 8 normal male Wistar Kyoto rats, undergone bilateral orchidectomy, then treated orally with DHEA $(30 \mathrm{mg} / \mathrm{kg})$ three times weekly for 12 weeks.

\section{The procedure of orchidectomy:}

Orchidectomy was done according to [20]. Anesthesia was prepared by mixing xylazine ( 9.1 $\mathrm{ml} / \mathrm{kg}$ ) with ketamine $(91 \mathrm{ml} / \mathrm{kg})$ in a dose of $10 \mathrm{ml}: 1 \mathrm{ml}$ respectively. The weight of each rat was taken and registered. Rats undergoing surgery were injected with anesthetics intraperitoneally in a dose 
of $0.1 \mathrm{ml}$ of anesthesia for every $100 \mathrm{gm}$ of the rat. After the rat is completely anesthetized it was fixed to the operating board on its back. Midline scrotal incision was performed. The parietal tunica was cut, and vaginal tunica cutting was avoided because it is intimately connected to the testis. Firm tug on the scrotal area was done until the testis comes out and ductus deferens, main arteries and veins were isolated, ligated and severed. The testes were ligated and cut and the testicular artery was ligated by sterile silk sutures. Finally, the incision was closed, sutured and swabbed with iodine. Each rat was put in a separate cage and had unrestricted access to water and food.

\section{Pharmacological treatment:}

DHEA was purchased from SIGMA and was used to treat the rats. $0.1 \mathrm{mg}$ of DHEA was dissolved in $10 \mathrm{ml}$ of distilled water to prepare the solution. $30 \mathrm{mg}$ of the solution was given by gastric gavage to every $\mathrm{kg}$ of the rat 3 times weekly for 12 weeks.

\section{Biochemical measurements:}

Blood samples:

After 12 weeks of treatment blood samples were taken under anesthesia by cardiac puncture. About $2 \mathrm{ml}$ of blood was taken from each rat and is collected in test tube without anticoagulant and is preserved in ice till it was transported the Biochemistry Teaching Lab at Sultan Qaboos University College of Medicine and Health Science. Serum was separated by the centrifugation for $30 \mathrm{~min}$ at $4000 \mathrm{rpm}$. Using the pipette, the serum of each rat was put in a cuvette and was stored at $-20^{\circ} \mathrm{C}$ in the physiology department's freezer.

Analyzer used was Cobas c1 11, Roche diagnostic, USA machine was used to measure the level of the Glucose, liver enzymes (ALP, AST and ALT) and lipid profile (Triglycerides, Cholesterol and HDL cholesterol) in the biochemistry teaching lab at Sultan Qaboos University's College of Medicine and Health Sciences. All the steps of calibration and quality control materials were taken according to the manufacturer's instructions.

Enzyme-Linked Immunosorbent Assay (ELISA) was used to measure the plasma level of testosterone hormone, insulin and glucose-6-phosphatase enzyme. All the steps of kit catalog were followed:

- Testosterone hormone kit catalog number: ab108666 (Cusabio).

- Insulin kit catalog number: \#90060(Crystal chemistry).

- Glucose-6-phosphatase enzyme kit catalog number: CSB-EL009118RA (abcam).

\section{Data analysis:}

The data was analyzed using descriptive analysis of simple bar charts by prism software. The Tukey's multiple comparison test was used to check for a significant statistical association between two variables. A $p$-value $<0.05$ shows that there is a statistically significant association between two variables.

\section{Results}

Effects of DHEA on plasma testosterone level in normal and orchidectomized rats:

Fig. (1) exhibit that there is a significant decrease $(p<0.05)$ in plasma level of testosterone in orchidectomized rats compared to the control rats. Control rats treated with DHEA shows insignificant changes $(p>0.05)$ in plasma level of testosterone when compared to control rats. While their plasma level of testosterone was significantly $(p<0.05)$ higher than orchidectomized rats. In orchiectomized rats treated with DHEA, plasma testosterone level was significantly $(p<0.05)$ decreased as compared to CON and CON + DHEA, while it was insignificantly $(p>0.05)$ increased versus ORCH group.

Effects of DHEA treatment on plasma level of Glucose in normal and orchidectomized rats:

Fig. (2) shows there is significant $(p<0.05)$ increase in plasma level of glucose in orchidectomized rats, control rats treated with DHEA and orchidectomized rats treated with DHEA as compared to the control rats. Glucose was not significantly changed between the ORCH, CON + DHEA as well as ORCH + DHEA.

\section{Effects of DHEA on plasma Insulin level in} normal and orchidectomized rats:

Fig. (3) shows that the plasma level of Insulin in orchidectomized rats and control rats treated with DHEA was significantly $(p<0.05)$ decreased compared to the control rats. Orchidectomized rats treated with DHEA shows significant $(p<0.05)$ elevation in the plasma level of insulin as compared to the control rats treated with DHEA.

Effects of DHEA treatment on plasma level of glucose-6 -phosphatase in normal and orchidectomized rats:

Fig. (4) shows there is insignificant $(p>0.05)$ increase in plasma level of glucose-6-phosphatase in orchidectomized rats compared with the control rats. The plasma level of glucose-6-phosphatase was insignificantly changed in orchidectomized rats treated with DHEA as compared with the control rats treated with DHEA. 


\section{Effects of DHEA on plasma level of lipid profile} in normal and orchidectomized rats:

Fig. (5A) shows there is a significant $(p<0.05)$ rise in plasma triglyceride $(\mathrm{mmol} / \mathrm{L})$ in orchidectomized rats and orchidectomized rats treated with DHEA as compared with the control rats. The plasma level of triglycerides of control rats treated with DHEA was significantly $(p<0.05)$ increase in comparison with orchidectomized rats.

Moreover, the cholesterol Fig. (5B) shows there is a significant $(p<0.05)$ elevation in plasma cholesterol $(\mathrm{mmol} / \mathrm{L})$ in orchidectomized rats and orchidectomized rats treated with DHEA as compared to the control rats. Also the plasma level of cholesterol of orchidectomized rats treated with DHEA was significantly $(p<0.05)$ increased in comparison to the control rats treated with DHEA.

Effects of DHEA on plasma liver enzymes levels in normal and orchiectomized rats:

Fig. (6) shows there are some insignificant ( $p$ $<0.05$ ) changes in the liver enzymes (AST, ALP and ALT) between the different groups.

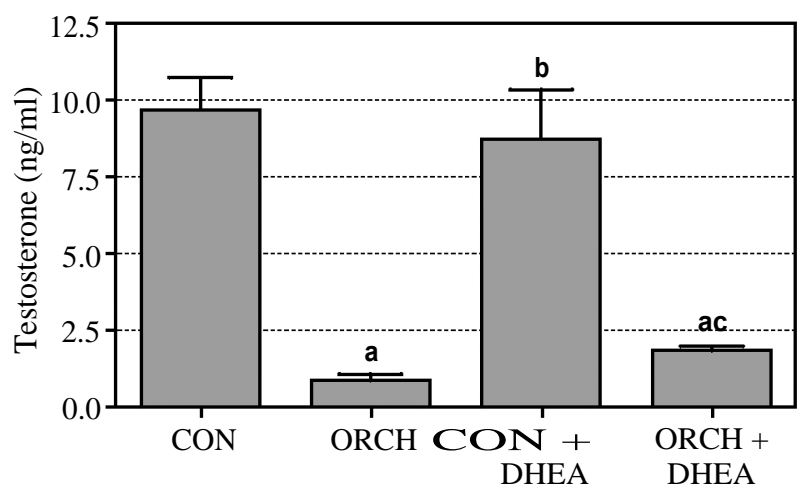

Fig. (1): Effects of DHEA on plasma testosterone level in normal and orchiectomized rats.

a: Significance relation vs control group.

b: Significance relation vs ORCH group.

c: Significance relation vs CON + DHEA group.

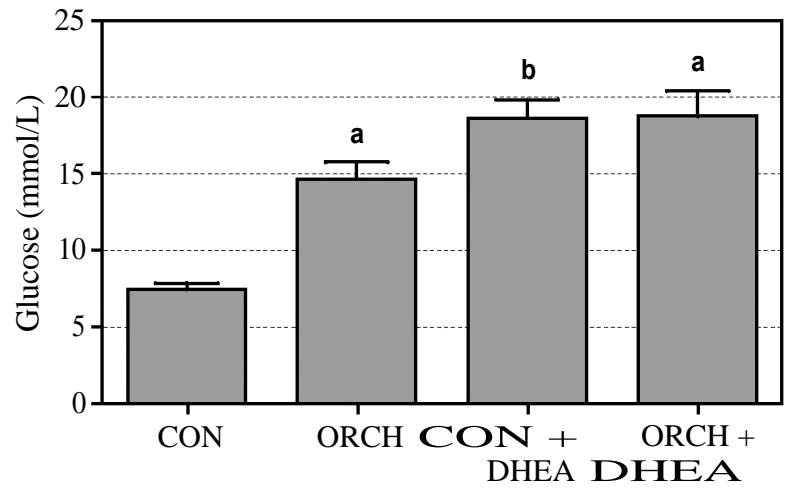

Fig. (2): Effects of DHEA on plasma Glucose level in normal and orchiectomized rats.

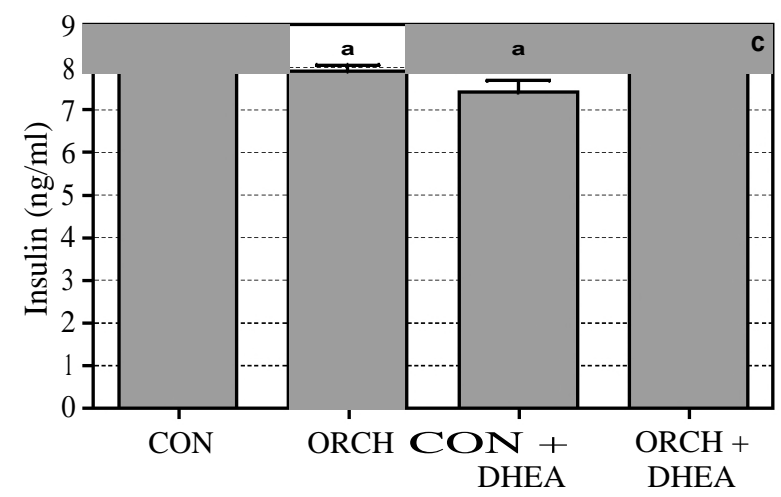

Fig. (3): Effects of DHEA on plasma insulin level in normal and orchidectomized rats.

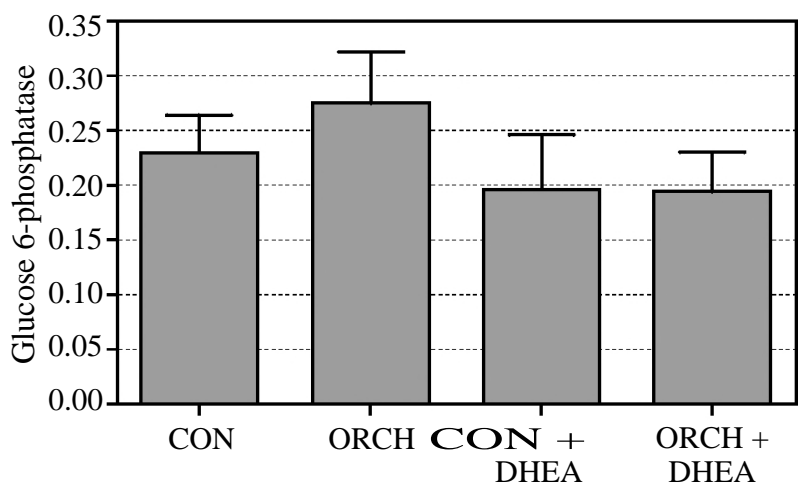

Fig. (4): Effects of DHEA on plasma level of glucose-6phosphatase enzyme in normal and orchidectomized rats.

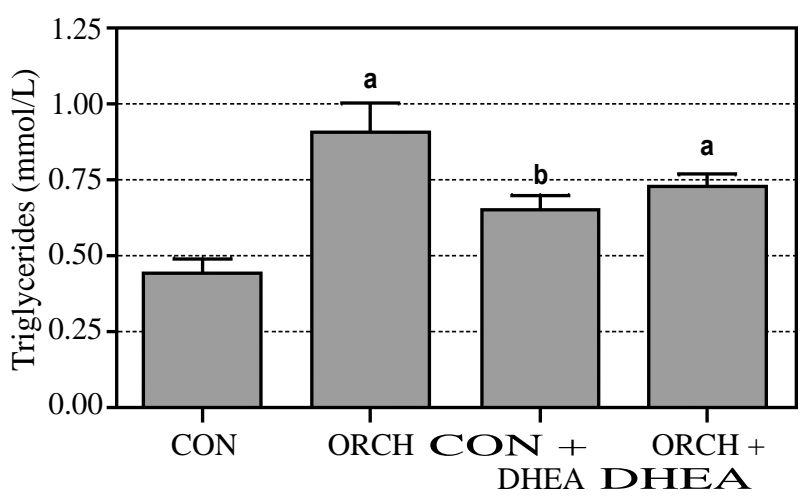

Fig. (5A): Effects of DHEA on plasma triglyceride level $(\mathrm{mmol} / \mathrm{L})$ in normal and orchiectomized rats.

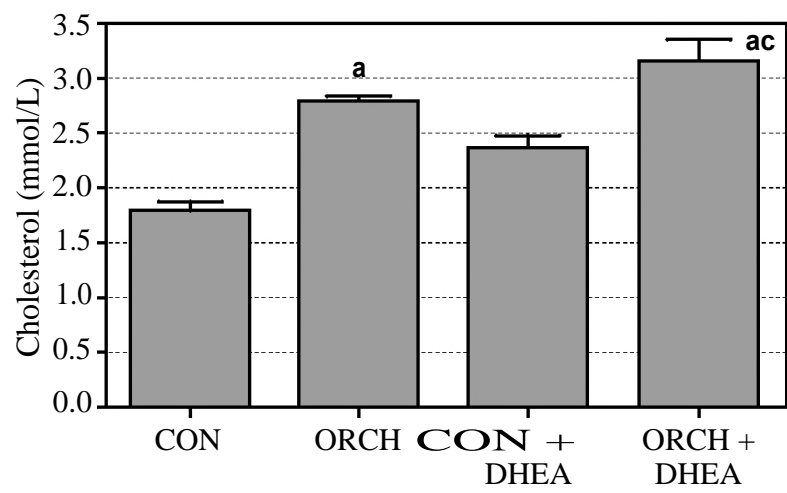

Fig. (5B): Effects of DHEA on plasma cholesterol level $(\mathrm{mmol} / \mathrm{L})$ in normal and orchiectomized rats. 

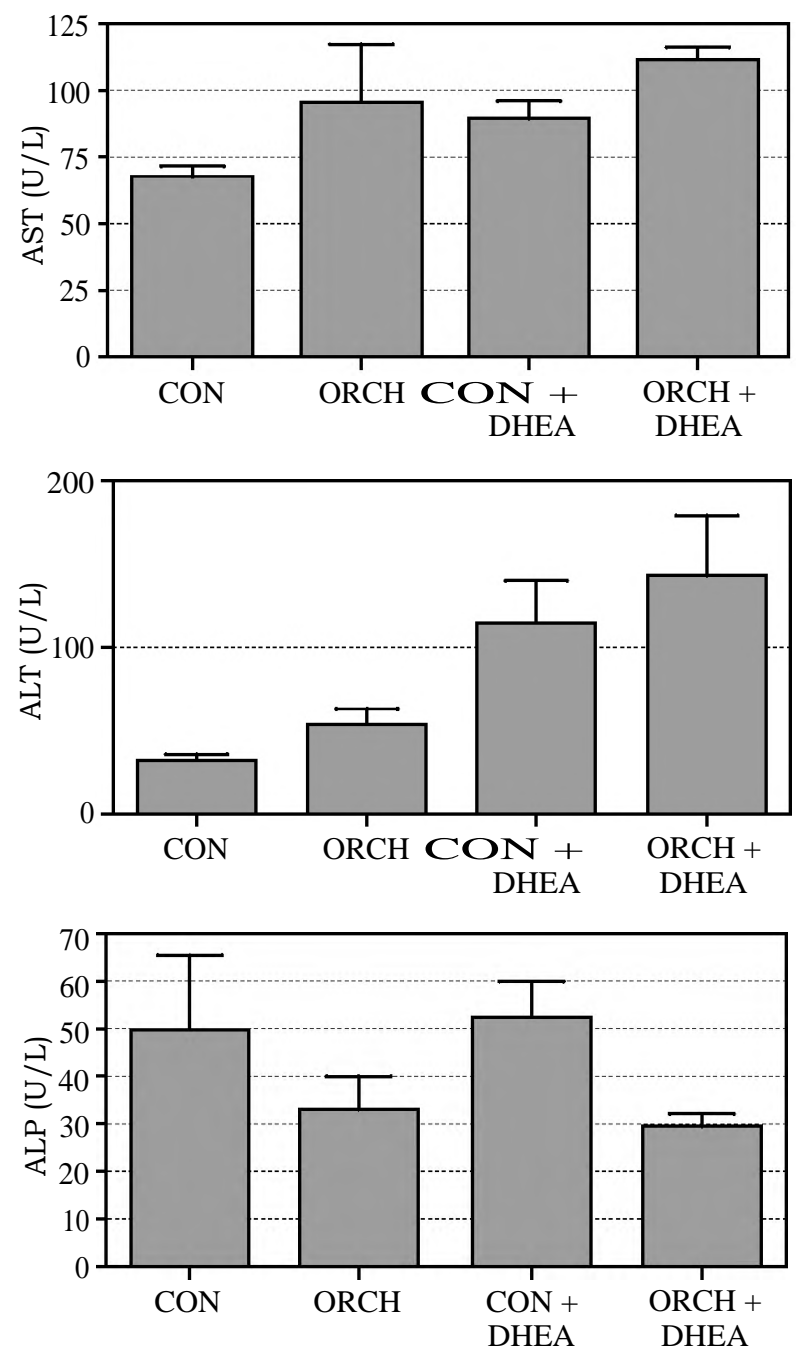

Fig. (6): Effects of DHEA on plasma level of liver enzymes in normal and orchiectomized rats.

\section{Discussion}

In the present work, we assessed the effect of DHEA as replacement therapy for male hypogonadism in rats. Our data showed that: 1- Male hypogonadism increased blood glucose, cholesterol and triglycerides; 2- DHEA treatment in control and orchidectomized rats has no effects on serum testosterone level; 3- Orchidectomy decreased insulin level; 4- DHEA has no effect on glucose 6 phosphatase expression.

Type 2 diabetes mellitus as well, as metabolic syndrome, are the most common endocrinal problems worldwide. Insulin resistance has a cardinal role in development of metabolic syndrome. There are several theories to discuss the roles of calories versus endocrine in the development of insulin insensitivity. Interaction between insulin and its receptors in hepatocytes, muscle fibers and adipocytes is markedly deteriorated before it is slowly decreased in the blood as a result of B cell exhaustion and type 2 diabetes mellitus development [21].

As expected orchidectomy decreased plasma testosterone level. Also, testosterone deficiency increased the plasma glucose level as compared with control rats. In agreement with these findings, [22].Testosterone deficiency and male hypogonadism are complicated by truncal obesity, visceral fat accumulation, hyperlipidemia, hypertension, type 2 diabetes mellitus and metabolic syndrome [7].

Our results can be explained by knowing the testosterone effects on carbohydrate metabolism. Testosterone increases insulin in the body which is necessary in stimulation of glucose transport into adipose and muscle tissue by previous studies [23]. Also, it increases GLUT4 expression and translocation in the cell membrane that is involved in glucose uptake from the blood. Moreover, testosterone increases the phosphorylation of protein kinase $\mathrm{C}$ which is a rate limiting step in the insulin receptor signaling pathway that is important for GLUT4 regulation and translocation [24]. Previous studies examined the role of low-dose of testosterone on adipocytes and skeletal muscle cells in short time incubation, they found upregulation of GLUT4 and IRS 1 [25]. Additionally, it was found that the testosterone increases the activity of hexokinase that is important for phosphorylation of glucose trapping it inside the skeletal muscle cells, and phosphofructokinase the major rate limiting step in glycolysis. As our results shows no increase in plasma testosterone in $\mathrm{ORCH}$ rats treated with DHEA it is expected of the glucose plasma level to increase as it did.

It is expected that DHEA replacement therapy will increase the testosterone plasma level in $\mathrm{ORCH}$ rats, but it didn't. Our data may be justified by the fact that the DHEA in males is mostly converted into estrogens at the [26] peripheral tissues like adipose and hepatic tissues rather than testosterone agreeing with a study that was done in Medical University Hospital Wuerzburg [27]. Morales et al., concluded that oral $100 \mathrm{mg}$ dose of DHEA for 6 months increased testosterone level in women, not in men [28]. Moreover, Villareal et al., documented that DHEA doubles the level of testosterone in women with a slight increase in men [29]. In meta-analysis study done by Corona et al., that the bioactivity of DHEA is the key factor in producing its biological effect neither the conversion to estradiol nor testosterone [30] 
Our results show a decrease in plasma insulin in ORCH rats compared to control. In contrast to our study [21], found that there is an increase in plasma level of insulin in ORCH rats. The depletion of insulin in our study may be due to exhaustion of B-cells of islets of Langerhans with chronic increase in plasma glucose level through of NFicB-activated COX-2/PGE2 up-regulation in AGEs/RAGE-induced islet endothelial cell apoptosis and cytotoxicity $[26,31]$. In ORCH + DHEA increased glucose leads to increase in insulin which was not significant change compared to $\mathrm{ORCH}$ rats. DHEA may exhibit a protective effect on Bcells [32]

G-6-Pase enzyme removes the phosphate group from the glucose-6-phosphate. The hydrolysis action of G-6-Pase enzyme enables the gluconeogenesis reaction to be completed and produces the free glucose by bypassing the irreversible hexokinase/glucokinase reaction [33]. Our results show insignificant difference between the groups. To the best of our knowledge, the present study is the first to demonstrate the effect of DHEA replacement therapy in the plasma level of G-6-Pase enzyme in a rat model of male hypogonadism. As G-6-Pase enzyme is mainly utterly an intracellular enzyme further investigation needed to measure the G-6Pase enzyme gene expression and proteins level in the hepatocyte by Polymerase Chain Reaction (PCR) and western plot.

Triglyceride increased in $\mathrm{ORCH}$ rats compared to control rats which was in agreement with the findings of previous results [34]. Our results suggest that testosterone deficiency increases the triglyceride synthesis and production. Testosterone deficiency accelerated the hepatic de novo lipogenesis through upregulating transcription factor SREBP1c, which promotes the expression of lipogenic genes including FAS, ACC, SCD1 and lipin $1[35,36]$ Acetyl-CoA Carboxylase (ACC) catalyses the conversion of acetyl-CoA to malonyl-CoA, whereas Fatty Acid Synthase (FAS) catalyses the formation of palmitic acid from malonyl-CoA and acetylCoA [37]

Senmaru et al., [38] demonstrated that testosterone regulates the hepatic Microsomal Triglyceride Transfer Protein (MTP) which plays a role in lipoprotein assembly.

In contrast to our study, Senmaru, et al., [38] found that testosterone deficiency decreases serum triglyceride. Triglyceride increased in control rats treated with DHEA compared to control rats. These findings cannot be compared to other similar studies because such investigations are not available. Since the testosterone didn't increase in ORCH rats treated with DHEA triglyceride plasma level is increased.

Cholesterol increased in ORCH rats compared to control rats. In agreement with our findings [21] Cholesterol increased may be due to upregulation of hepatic regulatory element-binding protein 2 (SREBP-2) which is responsible for direct activation of genes expression that are involved in the synthesis and uptake of cholesterol. Also, the HMGCoA reductase enzyme activity disrupted due to testosterone deficiency [38]. Since the testosterone didn't increase in ORCH rats treated with DHEA Cholesterol plasma level is increased.

In accordance to the results of Rice et al., [39], there wasn't any significant decrease or increase in the liver enzymes parameters in all groups suggesting no hepatic steatosis process and no side effect with DHEA. However, in contrast to our results, they found there is an elevation in liver enzymes, and the difference may be due to the duration of supplementation.

In conclusion, testosterone deficiency and DHEA replacement therapy not affect glucose 6phosphatase enzyme. Male hypogonadism is a risk factor for metabolic syndrome and NAFLD that could not be treated effectively with DHEA.

This work is part of the collaboration between the Department of Physiology, College of Medicine and Health Sciences, Sultan Qaboos University, Muscat, Oman and the Department of Clinical Pharmacology, College of Medicine, Mansoura University, Egypt.

\section{References}

1- SAKR H.F.: Modulation of metabolic and cardiac dysfunctions by swimming in overweight rats on a high cholesterol and fructose diet: Possible role of adiponectin. J. Physiol. Pharmacol., 64: 231-40, 2013.

2- POKRYWKA A., CHOLBINSKI P., KALISZEWSKI P., KOWALCZYK K., KONCZAK D. and ZEMBRONLACNY A.: Metabolic modulators of the exercise response: Doping control analysis of an agonist of the peroxisome proliferator-activated receptor delta (GW501516) and 5-aminoimidazole-4-carboxamide ribonucleotide (AICAR). J. Physiol. Pharmacol., 65: 469-76, 2014.

3- CHOI S. and DIEHL A.M.: Role of inflammation in nonalcoholic steatohepatitis. Curr. Opin. Gastroenterol., 21: 702-7, 2005.

4- PASCHOS P. and PALETAS K.: Non alcoholic fatty liver disease and metabolic syndrome. Hippokratia, 13: 9-19, 2009.

5- HUI J.M., HODGE A., FARRELL G.C., KENCH J.G., KRIKETOS A. and GEORGE J.: Beyond insulin resistance 
in NASH: TNF-alpha or adiponectin? Hepatology, 40: 46-54, 2004.

6- FAN J.G., ZHU J., LI X.J., CHEN L., LI L., DAI F., LI F. and CHEN S.Y.: Prevalence of and risk factors for fatty liver in a general population of Shanghai, China. J. Hepatol., 43: 508-14, 2005.

7- CORONA G., MANNUCCI E., FORTI G. and MAGGI M.: Hypogonadism, ED, metabolic syndrome and obesity: A pathological link supporting cardiovascular diseases. Int. J. Androl., 32: 587-98, 2009.

8- ELEAWA S.M., SAKR H.F., HUSSEIN A.M., ASSIRI A.S., BAYOUMY N.M. and ALKHATEEB M.: Effect of testosterone replacement therapy on cardiac performance and oxidative stress in orchidectomized rats. Acta Physiol., 209: 136-47, 2013.

9- HARING R., VOLZKE H., FELIX S.B., SCHIPF S., DORR M., ROSSKOPF D., NAUCK M., SCHOFL C. and WALLASCHOFSKI H.: Prediction of metabolic syndrome by low serum testosterone levels in men: Results from the study of health in Pomerania. Diabetes, 58: 2027-31, 2009.

10- BRAND J.S., VAN DER TWEEL I., GROBBEE D.E., EMMELOT-VONK M.H. and VAN DER SCHOUW Y.T.: Testosterone, sex hormone-binding globulin and the metabolic syndrome: A systematic review and metaanalysis of observational studies. Int. J. Epidemiol., 40: 189-207, 2011.

11- CORONA G., MONAMI M., RASTRELLI G., AVERSA A., TISHOVA Y., SAAD F., LENZI A., FORTI G., MANNUCCI E. and MAGGI M.: Testosterone and metabolic syndrome: A meta-analysis study. J. Sex Med., 8: 27283, 2011.

12- LAAKSONEN D.E., LINDSTRÖM J., LAKKA T.A., ERIKSSON J.G., NISKANEN L., et al.: Physical activity in the prevention of type 2 diabetes: The Finnish diabetes prevention study. Diabetes, Jan., 54 (1): 158-65, 2005.

13- HAYES F.J., DECRUZ S., SEMINARA S.B., BOEPPLE P.A. and CROWLEY W.F., JR.: Differential regulation of gonadotropin secretion by testosterone in the human male: Absence of a negative feedback effect of testosterone on follicle-stimulating hormone secretion. J. Clin. Endocrinol. Metab., 86: 53-8, 2001.

14- DEMIR O., AKGUL K., AKAR Z., CAKMAK O., OZDEMIR I., BOLUKBASI A., CAN E. and GUMUS B.H.: Association between severity of lower urinary tract symptoms, erectile dysfunction and metabolic syndrome. Aging Male, 12: 29-34, 2011.

15- ISIDORI A.M., GIANNETTA E., GRECO E.A., GIANFRILLI D., BONIFACIO V., ISIDORI A., LENZI A. and FABBRI A.: Effects of testosterone on body composition, bone metabolism and serum lipid profile in middle-aged men: A meta-analysis. Clin. Endocrinol., 63: 280-93, 2005.

16- PITTELOUD N., HARDIN M., DWYER A.A., VALASSI E., YIALAMAS M., ELAHI D. and HAYES F.J.: Increasing insulin resistance is associated with a decrease in Leydig cell testosterone secretion in men. J. Clin. Endocrinol Metab., 90: 2636-41, 2005.

17- GENAZZANI A.D., LANZONI C. and GENAZZANI A.R.: Might DHEA be considered a beneficial replacement therapy in the elderly? Drugs Aging, 24: 173-85, 2007.
18-DAVIS S.R., PANJARI M. and STANCZYK F.Z.: Clinical review: DHEA replacement for postmenopausal women. J. Clin. Endocrinol. Metab., 96: 1642-53, 2011.

19-PANJARI M. and DAVIS S.R.: DHEA therapy for women: Effect on sexual function and wellbeing. Hum Reprod Update, 13: 239-48, 2007.

20- KOJIMA T., DOI K., KISH M. and HORIGUCHI Y.: Sexrelated differences in plasminogen activator and plasminogen activator inhibiting activities in young and aged rats. Res. Commun. Mol. Pathol. Pharmacol., 104 (1): 81-91, 1999.

21- SAKR H.F., HUSSEIN A.M., EID E.A. and ALKHATEEB M.: Possible mechanisms underlying fatty liver in a rat model of male hypogonadism: A protective role for testosterone. Steroids, 135: 21-30, 2018.

22- RAMAMANI A., ARULDHAS M.M. and GOVINDARAJULU P.: Differential response of rat skeletal muscle glycogen metabolism to testosterone and estradiol. Can. J. Physiol. Pharmacol., 77: 300-4, 1999.

23- BRYANT N.J., GOVERS R. and JAMES D.E.: Regulated transport of the glucose transporter GLUT4. Nat. Rev. Mol. Cell Biol., 3: 267-77, 2002.

24- SATO K., IEMITSU M., AIZAWA K. and AJISAKA R.: Testosterone and DHEA activate the glucose metabolismrelated signaling pathway in skeletal muscle. Am. J. Physiol. Endocrinol. Metab., 294: 18, 2008.

25- CHEN X., LI X., HUANG H.Y. and LIN J.F.: Effects of testosterone on insulin receptor substrate-1 and glucose transporter 4 expression in cells sensitive to insulin. Zhonghua Yi Xue Za Zhi, 86: 1474-7, 2006.

26- GOLDIN A., BECKMAN J.A., SCHMIDT A.M. and CREAGER M.A.: Advanced glycation end products: Sparking the development of diabetic vascular injury. Circulation, 114: 597-605, 2006.

27- ARLT W., HAAS J., CALLIES F., REINCKE M., HUBLER D., OETTEL M., ERNST M., SCHULTE H. M. and ALLOLIO B.: Biotransformation of oral dehydroepiandrosterone in elderly men: Significant increase in circulating estrogens. J. Clin. Endocrinol. Metab., 84: 2170-6, 1999 .

28- MORALES A.J., HAUBRICH R.H., HWANG J.Y., ASAKURA H. and YEN S.S.: The effect of six months treatment with a $100 \mathrm{mg}$ daily dose of dehydroepiandrosterone (DHEA) on circulating sex steroids, body composition and muscle strength in age-advanced men and women. Clin. Endocrinol., 49: 421-32, 1998.

29- VILLAREAL D.T., HOLLOSZY J.O. and KOHRT W.M.: Effects of DHEA replacement on bone mineral density and body composition in elderly women and men. Clin. Endocrinol., 53: 561-8, 2000.

30- CORONA G., RASTRELLI G., GIAGULLI V.A., SILA A., SFORZA A., FORTI G., MANNUCCI E. and MAGGI M.: Dehydroepiandrosterone supplementation in elderly men: A meta-analysis study of placebo-controlled trials. J. Clin. Endocrinol. Metab., 98: 3615-26, 2013.

31- LAN K.C., CHIU C.Y., KAO C.W., HUANG K.H., WANG C.C., HUANG K.T., TSAI K.S., SHEU M.L. and LIU S.H.: Advanced glycation end-products induce apoptosis in pancreatic islet endothelial cells via NF-kappaBactivated cyclooxygenase-2/prostaglandin E2 upregulation. PLoS One, 10, 2015. 
32- GIROIX M.H., MALAISSE-LAGAE F., PORTHA B., SENER A. and MALAISSE W.J.: Effects of dehydroepiandrosterone in rats injected with streptozotocin during the neonatal period. Biochem. Mol. Med., 61: 72-81, 1997.

33- MARCOLONGO P., FULCERI R., GAMBERUCCI A., CZEGLE I., BANHEGYI G. and BENEDETTI A.: Multiple roles of glucose-6-phosphatases in pathophysiology: State of the art and future trends. Biochim. Biophys. Acta, 3, 013, 2013.

34- WU F.C. and VON ECKARDSTEIN A.: Androgens and coronary artery disease. Endocr. Rev., 24: 183-217, 2003.

35- HOYOS C.M., YEE B.J., PHILLIPS C.L., MACHAN E.A., GRUNSTEIN R.R. and LIU P.Y.: Body compositional and cardiometabolic effects of testosterone therapy in obese men with severe obstructive sleep apnoea: A randomised placebo-controlled trial. Eur. J. Endocrinol., 167: 531-41, 2012.

36- NIKOLAENKO L., JIA Y., WANG C., DIAZARJONILLA M., YEE J.K., FRENCH S.W., LIU P.Y.,
LAUREL S., CHONG C., LEE K., LUE Y., LEE W.N. and SWERDLOFF R.S.: Testosterone replacement ameliorates nonalcoholic fatty liver disease in castrated male rats. Endocrinology, 155: 417-28, 2014.

37- MARI M., CABALLERO F., COLELL A., MORALES A., CABALLERIA J., FERNANDEZ A., ENRICH C., FERNANDEZ-CHECA J.C. and GARCIA-RUIZ C.: Mitochondrial free cholesterol loading sensitizes to TNFand Fas-mediated steatohepatitis. Cell Metab, 4: 185-98, 2016.

38- SENMARU, TAKAFUMI, et al.: Testosterone deficiency induces markedly decreased serum triglycerides, increased small dense LDL, and hepatic steatosis mediated by dysregulation of lipid assembly and secretion in mice fed a high-fat diet. Metabolism-Clinical and Experimental, 62.6: 851-60, 2013.

39- RICE, SAM P.L., et al.: Effects of dehydroepiandrosterone replacement on vascular function in primary and secondary adrenal insufficiency: A randomized crossover trial. The Journal of Clinical Endocrinology \& Metabolism, 94.6: 1966-72, 2009.

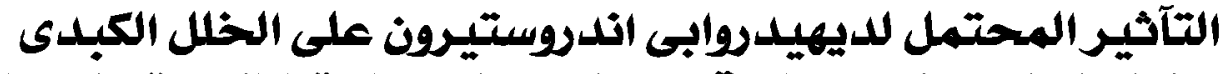

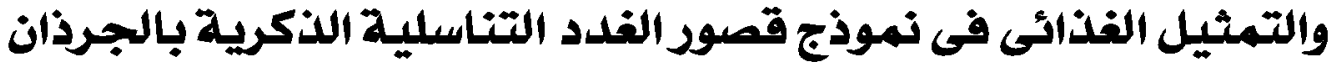

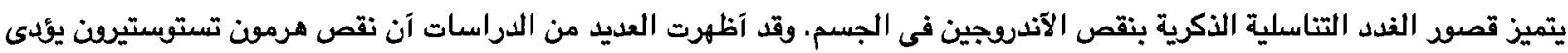

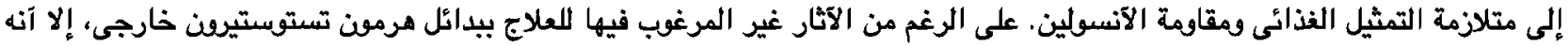

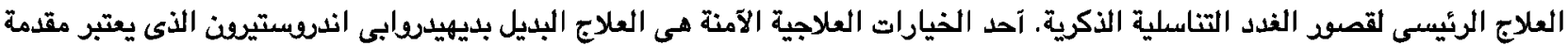

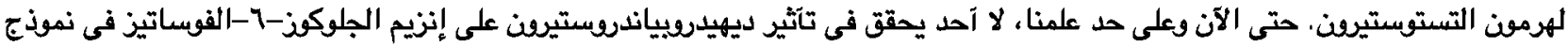
الفتران من قصور الغدد التناسلية الذكرية وتآثيره على ضعف لآني التمثيل الغذائى.

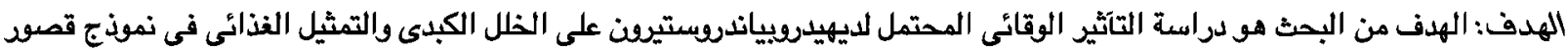

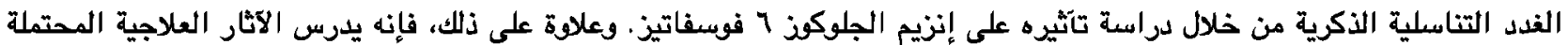

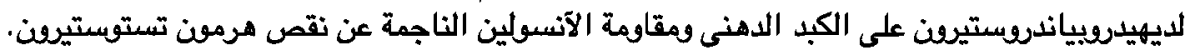

$$
\begin{aligned}
& \text { الطريقة: تم تقسيم إثنين وثُلاثين من الفتران إلى ع مجموعات على النحو التالى: } \\
& \text { (1) (1) مجموعة ضابطة سالبة. }
\end{aligned}
$$

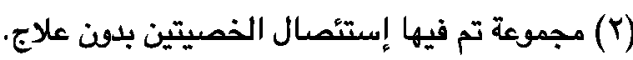

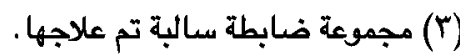

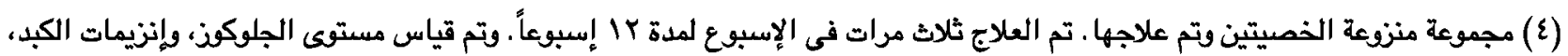

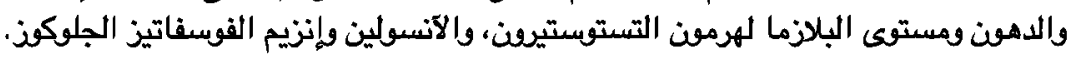

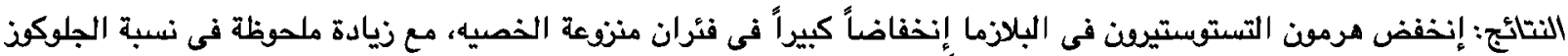

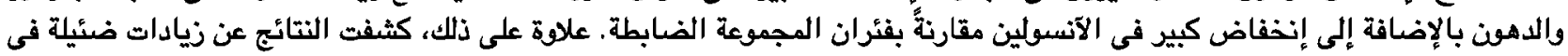

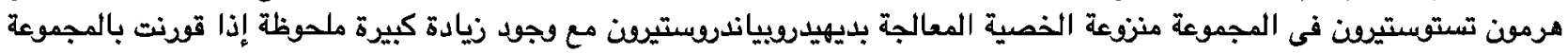

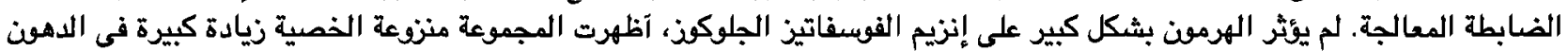

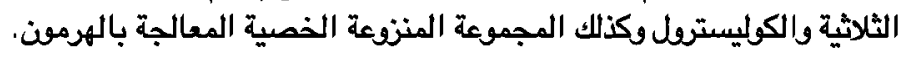

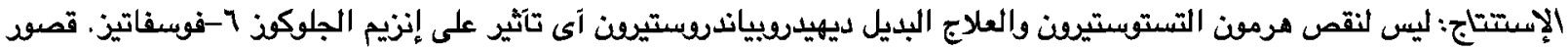

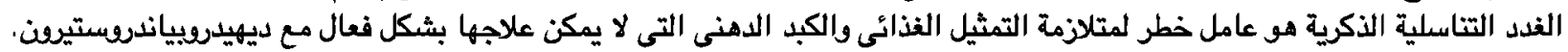

